\title{
RESEARCH
}

Open Access

\section{Peripheral blood-derived monocytes show neuronal properties and integration in immune-deficient rd1 mouse model upon phenotypic differentiation and induction with retinal growth factors}

\author{
Alaknanda Mishra', K. Varsha Mohan', Perumal Nagarajan', Srikanth lyer ${ }^{1}$, Ashwani Kesarwani ${ }^{1}$, Madhu Nath², \\ Laxmi Moksha², Jashdeep Bhattacharjee ${ }^{1}$, Barun Das ${ }^{1}$, Kshama Jain', Parul Sahu', Prakriti Sinha', \\ T. Velapandian ${ }^{2}$ and Pramod Upadhyay ${ }^{1 *}$ (D)
}

\begin{abstract}
Background: Cell therapy is one of the most promising therapeutic interventions for retinitis pigmentosa. In the current study, we aimed to assess if peripheral blood-derived monocytes which are highly abundant and accessible could be utilized as a potential candidate for phenotypic differentiation into neuron-like cells.

Methods: The peripheral blood-derived monocytes were reconditioned phenotypically using extrinsic growth factors to induce pluripotency and proliferation. The reconditioned monocytes (RM) were further incubated with a cocktail of growth factors involved in retinal development and growth to induce retinal neuron-like properties. These cells, termed as retinal neuron-like cells (RNLCS) were characterized for their morphological, molecular and functional behaviour in vitro and in vivo.

Results: The monocytes de-differentiated in vitro and acquired pluripotency with the expression of prominent stem cell markers. Treatment of RM with retinal growth factors led to an upregulation of neuronal and retinal lineage markers and downregulation of myeloid markers. These cells show morphological alterations resembling retinal neuron-like cells and expressed photoreceptor (PR) markers. The induced RNLCs also exhibited relative membrane potential change upon light exposure suggesting that they have gained some neuronal characteristics. Further studies showed that RNLCs could also integrate in an immune-deficient retinitis pigmentosa mouse model NOD.SCID-rd1 upon sub-retinal transplantation. The RNLCs engrafted in the inner nuclear layer (INL) and ganglion cell layer (GCL) of the RP afflicted retina. Mice transplanted with RNLCs showed improvement in depth perception, exploratory behaviour and the optokinetic response.
\end{abstract}

(Continued on next page)

\footnotetext{
*Correspondence: pkumar@nii.ac.in

'National Institute of Immunology, Aruna Asaf Ali Marg, New Delhi 110067, India

Full list of author information is available at the end of the article
}

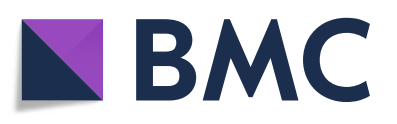

(- The Author(s). 2020 Open Access This article is licensed under a Creative Commons Attribution 4.0 International License, which permits use, sharing, adaptation, distribution and reproduction in any medium or format, as long as you give appropriate credit to the original author(s) and the source, provide a link to the Creative Commons licence, and indicate if changes were made. The images or other third party material in this article are included in the article's Creative Commons licence, unless indicated otherwise in a credit line to the material. If material is not included in the article's Creative Commons licence and your intended use is not permitted by statutory regulation or exceeds the permitted use, you will need to obtain permission directly from the copyright holder. To view a copy of this licence, visit http://creativecommons.org/licenses/by/4.0/ The Creative Commons Public Domain Dedication waiver (http://creativecommons.org/publicdomain/zero/1.0/) applies to the data made available in this article, unless otherwise stated in a credit line to the data. 
(Continued from previous page)

Conclusions: This proof-of-concept study demonstrates that reconditioned monocytes can be induced to acquire retinal neuron-like properties through differentiation using a defined growth media and can be a potential candidate for cell therapy-based interventions and disease modelling for ocular diseases.

Keywords: Retinitis pigmentosa, Human peripheral blood monocytes, Retinal neuron-like cells, Visual activity, rd1 mouse model

\section{Background}

Retinitis pigmentosa $(\mathrm{RP})$ is a progressive irreversible retinal degenerative disease which causes partial or complete blindness [1, 2]. This phenomenon predominantly affects rod photoreceptors, and subsequently, other retinal cells are also affected [3]. Mutations in the gene PDE6B encoding for the $\beta$-subunits of phosphodiesterase 6 enzyme cause autosomal recessive RP. Hence, the mechanisms that initiate accumulation of cGMP and calcium are thought to cause rod-cone degeneration in Pde6b-/- RP patients [4].

Currently, the condition is incurable, and the treatment modules offer only symptomatic relief. Some of the treatment approaches include neuroprotective strategies $[5,6]$, gene therapy [5], prosthetic devices [7, 8], and stem cell therapies $[2,9,10]$. Reports have shown that cell therapy could not only replenish the degenerated retina but the transplanted cells could also form synaptic connections with the preserved population of cells [10]. Besides, cell-based therapy can benefit multiloci genetic mutations by possibly recreating the natural anatomy and circuitry of retina.

However, it is difficult to find an accessible and abundant source of cells using minimally invasive techniques for this purpose. Patient-specific iPSCs are currently under intense scrutiny for their unpredictable genomic instability [11] while ESCs have various ethical issue concerns [12]. The patient-specific retinal somatic tissue obtained from cadavers or after retinal biopsies obtained during intraocular retinectomy are usually inadequate for disease modelling or drug screening.

The monocytes comprise 5-8\% of blood, thus yielding a larger endpoint population. Monocytes are promising target for differentiation into neuronal lineages due to established fact that (i) there is no need for viral insertion (or other non-integrative techniques) that is known to cause methylation abnormalities as well as mutations $[13,14]$, (ii) they have a shorter time of differentiation from somatic cell to neuronal-like cell when compared to iPSC [15], and (iii) preliminary results indicating monocytes deliver reproducibility with serial samples from the same individual [15] which continues to be a challenge with iPSCs [16-18].

Therefore in our present study, we aimed to assess the potential of monocytes obtained from peripheral blood to differentiate without genetic modification, to stem celllike cells as reported earlier [19]. Thereafter, we induced the reconditioned monocytes with extrinsic factors involved in retinal differentiation towards a state mimicking retinal neuron-like cells. The term reconditioning/differentiation in this study refers to phenotypic alteration and/ or induction of cells without genetic manipulation. RNLCs were studied for molecular, phenotypic and functional properties in vitro followed by transplantation in an immune-deficient rd1 mouse model previously developed in our lab [20] to test their integration in vivo. We also checked if these induced RNLCs could gain retinal neuron-like function when aided by an ocular microenvironment upon transplantation.

\section{Materials and methods}

Ethical clearance for use of human blood samples and animal experiments

Ethical clearance was obtained from Institutional $\mathrm{Hu}$ man Ethics Committee of National Institute of Immunology, New Delhi, for procuring buffy coat of healthy blood samples (IHEC\#85/14). Approval to perform animal experiments was obtained from Institutional Animal Ethics Committee of National Institute of Immunology, New Delhi (IAEC\#334/14).

\section{Animal housing and breeding}

All the mice required during different experiments (NOD.CB17-Prkdcscid/J (NOD SCID), CBA/J and $\mathrm{BALB} / \mathrm{cByJ}(\mathrm{BALB} / \mathrm{c})$ were procured from the Jackson Laboratory, USA while the NOD-SCID-rd1 mouse model was developed in-house as reported previously [20]. The animals received ad libitum access to acidified autoclaved water and food. The temperature and humidity of the housing room was maintained at $21-23^{\circ} \mathrm{C}$ and 40-60\% respectively. Animals were kept at a 14-h light to 10 -h dark cycle. Animals were randomly assigned in each group, and experiments were repeated at least twice. All animal experiments and reporting adhere to the ARRIVE guidelines [21].

\section{Peripheral blood mononuclear cell (PBMC) isolation} The buffy coat of the blood donated by healthy volunteers was obtained from the blood bank of All India Institute of Medical Sciences (AIIMS), New Delhi. The 
samples were negative for human immunodeficiency virus (HIV), hepatitis B virus (HBV) and hepatitis C virus $(\mathrm{HCV})$. PBMCs were isolated from buffy coat by density centrifugation technique using Hisep ficoll (HiMedia, India; $1.077 \mathrm{~g} / \mathrm{cm}^{3}$ ) and washed with PBS before plating for monocyte enrichment. The isolated PBMCs isolated from the buffy coat were plated for overnight in IMDM supplemented with 5\% fetal bovine serum (FBS) (Gibco, USA) in T-150 flasks and incubated at $37^{\circ} \mathrm{C}$ and $5 \% \mathrm{CO}_{2}$. The non-adherent cells were discarded, and the adherent cells were washed twice with PBS to ensure removal of any non-adherent cells. The adherent cells were isolated by trypsinization $(0.25 \%$ trypsin) and centrifuged at $300 \mathrm{~g}$ for $10 \mathrm{~min}$ at $4{ }^{\circ} \mathrm{C}$. The pellet obtained was re-suspended in incomplete IMDM media, and cells were counted using trypan blue. To obtain highly pure monocyte cell population, the adherent cells were sorted for CD14+ cells using FACS ARIA II (BD Biosciences, USA).

\section{Viability characterization}

The adherent cells were checked for viability by annexinA5 and propidium iodide (PI) staining according to the manufacturer's instruction (BD Biosciences, USA). Briefly, $1 \times 10^{6}$ cells were diluted in $1 \mathrm{X}$ annexin-binding buffer and $5 \mu \mathrm{L}$ FITC annexin V (Component A) and $1 \mu \mathrm{L}$ PI working solution $(100 \mu \mathrm{g} / \mathrm{mL})$ was added to $100 \mu \mathrm{L}$ cell suspension. The cells were incubated at room temperature for $15 \mathrm{~min}$, and the reaction was stopped by adding $400 \mu \mathrm{L}$ of $1 \mathrm{X}$ annexin-binding buffer. After mixing it gently, the samples were kept on ice. The stained samples were analysed immediately by flow cytometry (FACS Verse), and data was analysed using FlowJo ${ }^{\circ}$.

\section{Differentiation of monocytes into RNLCs}

$1 \times 10^{6}$ cells/ well were seeded in human fibronectin coated $\left(5 \mu \mathrm{g} / \mathrm{cm}^{2}\right)$ 12-well plates supplemented with culture media prepared in IMDM supplemented with IL3 (4 ng/ml), MCSF $(5 \mathrm{ng} / \mathrm{ml}), 2-\mathrm{ME}(140 \mu \mathrm{M})$ and embryonic stem cell grade serum (0.5\%). The obtained reconditioned monocytes (RM) obtained post 6 days of cell culture and were induced towards neuronal lineage by culturing them in DMEM/F-12 supplemented with b-FGF ( $20 \mathrm{ng} / \mathrm{ml})$, Retinoic acid $(0.1 \mu \mathrm{g} / \mathrm{ml})$, EGF $(20 \mathrm{ng} / \mathrm{ml})$, IGF-1 $(20 \mathrm{ng} / \mathrm{ml})$, SCF $(20 \mathrm{ng} / \mathrm{ml})$, Taurine $(100 \mu \mathrm{M})$, B27 supplement $(2 \%)$, ESC serum (0.5\%), MEM-NEAA (1x) and antibiotics (1\%) for 8 days. Media was changed every 3 days during the culture tenure. Manufacturer's information for growth factors and supplements is provided in Table 8.

\section{Morphological studies}

The morphology of the cells was imaged using a phase contrast microscope at $\times 10$ and $\times 20$ resolution for different stages of culture tenure. The morphology of cells at each stage was reconfirmed by scanning electron microscopy (Zeiss, at $20 \mathrm{kV}$ and $4.97 \mathrm{Kx}$ magnification). The method for SEM analysis has been detailed in Supplementary data file.

\section{MTT assay}

Cells were plated at $5 \times 10^{5}$ cells/well concentration and incubated overnight for adherence. DMEM-F12 media containing $0.5 \mathrm{mg} / \mathrm{ml}$ MTT (3-(4,5-dimethylthiazol-2yl)-2,5-diphenyl tetrazolium bromide) was added to the cells and incubated for $3 \mathrm{~h}$ at $37^{\circ} \mathrm{C}$. The blue formazan crystals were dissolved in dimethyl sulphoxide (DMSO), and absorbance was measured at $570 \mathrm{~nm}$.

\section{qPCR analysis}

The cells were harvested by trypsinization $(0.25 \%$ trypsin) and RNA was isolated using TRI Reagent (Sigma, USA) as per the manufacturer's protocol. RNA pellet obtained post spin was then washed twice with 70\% alcohol, air dried and resuspended in nuclease-free water. cDNA was prepared using cDNA synthesis kit (Biorad, USA) according to the manufacturer's protocol, and real-time PCR was performed using DyNAmo Flash SYBRGreen (Thermo Fisher Scientific, USA) on the Mastercycler ${ }^{\circ}$ Realplex platform (Eppendorf, Germany). Primers are tabulated in supplementary data file Table 2-7.

\section{Flow cytometry}

The adherent cells $\left(1 \times 10^{6}\right.$ cells $)$ were harvested and resuspended in $100 \mu \mathrm{l}$ of a cocktail of anti-human cell surface marker antibodies at a dilution of 1:200 in PBS and mixed gently. The cells were incubated at $4{ }^{\circ} \mathrm{C}$ for 40 min in dark. The stained cells were washed with 1X PBS after incubation and analysed immediately.

For evaluation of intracellular markers, fresh fixation/permeabilization solution was prepared by diluting the fix/perm concentrate with diluent at a ratio of 1:3 (BD bioscience, USA). One millilitre Fix/Perm solution was added to each sample, incubated for $1 \mathrm{~h}$ protected from light and centrifuged at $300 \mathrm{~g}$ for 5 min at RT. The cells were washed and blocked with $2 \%$ FBS in permeabilization buffer for $15 \mathrm{~min}$. The cells were washed again, and appropriate dilutions of antibodies were added and incubated for $30 \mathrm{~min}$ at RT in dark. The samples were washed and incubated in $100 \mu \mathrm{l}$ of secondary antibody for $20 \mathrm{~min}$ at RT. Appropriate single-colour controls and secondary antibody controls were also prepared. The samples were washed and run on BD FACSVerse ${ }^{\mathrm{m}}$. The data was analysed using FACS Diva software. The antibodies are tabulated in Supplementary data file Table 1. 


\section{5-Ethynyl-2'-deoxyuridine (EDU) proliferation assay}

EDU (5-ethynyl-2'-deoxyuridine) cell proliferation assay was performed using Click-It EDU-Alexa Fluor 488 assay kit as per the manufacturer's instruction (Thermo fisher scientific, USA). Briefly, the cells were plated at an optimum density and EDU was added to the culture medium at a concentration of $10 \mu \mathrm{M}$, mixed well and incubated for 1-2 h. The EDU-treated cells were washed with $3 \mathrm{ml}$ of $1 \%$ BSA in PBS and cells were pelleted. One hundred microlitres of fixative (Component D) was added to the pellet, vortexed and incubated for $15 \mathrm{~min}$ at $\mathrm{RT}$ in dark followed by a wash with $1 \%$ BSA in PBS and centrifuged to obtain a pellet. The cell pellet was resuspended in $1 \mathrm{X}$ Click-It permeabilization buffer and incubated for $15 \mathrm{~min}$ at RT. The permeabilized cells were washed with $3 \mathrm{ml}$ of $1 \mathrm{X}$ Click IT saponin-based wash reagent, centrifuged and resuspended in PBS. The samples were run in FACS Verse and analysed by Flowjo 10 software for Alexa Fluor 488 positive cells.

\section{Western blotting}

The isolated cells were lysed in RIPA lysis buffer and centrifuged, the supernatant was collected and protein estimation using BCA kit (G-Biosciences, USA) was performed according to the manufacturer's instructions. The samples were run on 10\% SDS-Polyacrylamide gel and transferred to a PVDF membrane. The membrane was incubated overnight in primary antibody at $4{ }^{\circ} \mathrm{C}(1$ : 1000) followed by $3 \mathrm{X}$ washes for $10 \mathrm{~min}$ each and further incubated for $2 \mathrm{~h}$ in anti-mouse/rabbit secondary antibody (1:1000) conjugated with HRP. After 2 washes with PBST, the blot was treated with ECL substrate mixture (Thermo Fisher Scientific, USA) for $5 \mathrm{~min}$ in dark and developed using a ChemiDoc ${ }^{\mathrm{TM}}$ (Biorad, USA). The antibodies utilized are tabulated in Supplementary data file Table 1.

\section{Immunocytochemistry (ICC)}

The cells were fixed with $4 \%$ PFA for $30 \mathrm{~min}$ at $4{ }^{\circ} \mathrm{C}$ in dark. The fixed cells were permeabilized for $45 \mathrm{~min}$ using permeabilization buffer containing $0.1 \%$ saponin, followed by washing and blocking with 5\% BSA for 45 min at RT. The cells were washed with wash buffer and incubated in primary antibodies (Supplementary data file Table 1) diluted at proper optimized concentrations for an hour at RT or overnight at $4{ }^{\circ} \mathrm{C}$. After 3 washes with PBS, the cells were incubated with a fluorochromelabelled secondary antibody for 40-45 min at RT, washed thrice with PBS and counterstained with DAPI (dilution 1:500; Concentration: $1 \mathrm{mg} / \mathrm{ml}$ ) for $5 \mathrm{~min}$ at RT. The cells were mounted with coverslips using Vectashield ${ }^{\ominus}$. Representative images were captured using a fluorescent microscope $(\times 40)$ or a confocal microscope $($ LSM Zeiss 510$)$ at $\times 63$.
Potentiometric dye-based study of relative membrane potential changes in photopic and scotopic conditions We prepared $5 \mu \mathrm{M} \mathrm{DiBAC}_{4}$ (3) with $20 \%$ Pluronic $^{\oplus} \mathrm{F}-127$ in $1 \mathrm{ml}$ culture medium (Stock concentration of dye was $100 \mu \mathrm{M})$. The cells were loaded with $5 \mu \mathrm{l}$ of dye solution and incubated in dark for $5 \mathrm{~min}$. The control samples included untreated control to which only DMSO was added, hyperpolarization control to which $10 \mu \mathrm{l}$ of $1 \mathrm{mM}$ valinomycin was added and depolarization control to which $10 \mu \mathrm{l}$ of $1 \mathrm{mM}$ gramicidin was added. Autofluorescence was compensated using an only dye-treated control. The samples incubated in light and dark conditions were used to observe membrane potential changes in light/dim conditions. The samples were analysed by flow cytometry (FACSVerse ${ }^{\mathrm{Tm}}$ ) and fluorescence was measured.

\section{Carboxyfluorescein succinimidyl ester (CFSE) labelling of RNLC prior to transplantation}

CFSE was used for labelling the RNLCs before transplantation. The cells were isolated, washed with $1 \mathrm{X}$ PBS and enumerated. A working concentration of $20 \mu \mathrm{M}$ of CFSE in HBSS was prepared and added to the cells. The cells were incubated with CFSE for $15 \mathrm{~min}$ at $37^{\circ} \mathrm{C}$. The labelling reaction was quenched by adding 5 volumes of cold complete media and incubated on ice for $5 \mathrm{~min}$, protected from light. The stained cells were centrifuged at $300 \mathrm{~g}$ for $5 \mathrm{~min}$ at RT and washed twice with PBS before use.

\section{Cell engraftment analysis}

The engraftment efficiency of transplanted cells in RP mouse model was evaluated by fluorescent imaging and qPCR analysis. qPCR was performed using a human GAPDH-specific TaqMan probe. The details of qPCR methodology, primers and setup conditions are given in the Supplementary data file.

\section{Fluorescent in situ hybridization (FISH)}

The animals were euthanized, and the eyes were enucleated, washed and fixed in freshly prepared 4\% PFA. The tissue samples were embedded in OCT (optimum cutting temperature) medium and cryo-sectioned to obtain $5 \mu \mathrm{m}$ sections on L-poly-lysine coated slides.

The biotin labelled DNA probe was added to the tissue section, covered with a cover glass and sealed using rubber cement. The slides were hybridized at $37^{\circ} \mathrm{C}$ for $16-$ $24 \mathrm{~h}$. The cover glass was then removed and the slides were washed. After washing, the slides were incubated with secondary antibody (conjugated with Streptavidin Alexa Fluor 594) staining followed by counterstaining with DAPI. The slides were mounted with coverslip and visualized and imaged in confocal microscope (Zeiss 
LSM) at $\times 63$ magnification. Detailed method is provided in the Supplementary data file.

\section{c-GMP analysis}

c-GMP concentration was measured using DetectX $\mathrm{X}^{\bullet}$ cGMP colorimetric kit (Arbor Assays, USA, Cat: K020H1) from serum and eye lysate samples of nontransplanted and transplanted animals as per the manufacturer's protocol. Briefly, we prepared standards from stock c-GMP solution $(640 \mathrm{pmol} / \mathrm{mL})$ by serial dilution at 20-fold dilution with each step to obtain concentrations ranging from 32 to $0.5 \mathrm{pM} / \mathrm{ml}$. The standards were used within $1 \mathrm{~h}$ of preparation. Samples were prepared by diluting them appropriately in assay diluent. Fifty microlitres of plate primer was added in the wells followed by adding $75 \mu \mathrm{l}$ of sample diluent into the nonspecific binding (NSB) wells. Fifty microlitres of sample diluent was added into the maximum binding (B0) wells. Fifty microlitres of samples or standards was dispensed into the wells, and $25 \mu \mathrm{l}$ of Detect $\mathrm{X}^{\odot}$ cGMP conjugate was added to each well followed by addition of $25 \mu \mathrm{l}$ of Detect $\mathrm{X}^{\bullet}$ cGMP antibody except NSB wells. The plate was gently tapped from the sides to ensure adequate mixing of the reagents. The plate was covered with plate sealer and kept at shaker for $2 \mathrm{~h}$ at RT. The wells were aspirated, washed four times with $300 \mu \mathrm{l}$ wash buffer and tapped dry. Further, 100 ul of TMB (Tetramethylbenzidine) substrate was added to each well and incubated at $\mathrm{RT}$ for $30 \mathrm{~min}$. The reaction was quenched by adding $50 \mu \mathrm{l}$ stop solution. The absorbance maxima were read at $450 \mathrm{~nm}$, and standard curve was plotted. cGMP concentration was calculated.

\section{Transplantation via trans-corneal subretinal injection}

NOD.SCID-rd1 mice (4-6 weeks) of any gender (2:1 male to female ratio) were used for the experiments. The cornea was topically anaesthetized by one drop of proparacaine hydrochloride ophthalmic solution $(0.5 \%)$. A single drop of tropicamide ophthalmic solution (1\%) was used to dilate pupil. The animal was anaesthetized using ketamine $(80-100 \mathrm{mg} / \mathrm{kg})$ and xylazine $(10 \mathrm{mg} / \mathrm{kg})$ intraperitoneally. After anaesthetizing, the mouse was placed in lateral recumbence with the eye to be injected facing up. The skin was retracted towards the body causing the eye to protrude. The needle bevel was inserted up into the corneal of the eye at a 45 degree angle to relieve ocular pressure. The cell suspension of 1 million RNLCs was injected into the sub-retinal region. After injection, ophthalmic Tobrex ointment/povidine-iodine (5\% solution) was applied along with antibiotic solution on the mouse eye to prevent infection. The animals were placed in IVC cages and monitored for viability and signs of eye infections like redness, keratitis and puffiness. We injected only one eye for IHC, FISH and cell engraftment quantification while both eyes were injected for behavioural analysis. The non-transplanted animals were used as negative control in behavioural studies.

\section{Immunohistochemistry}

Whole eye was enucleated from the animals after euthanasia by cervical dislocation. The tissue was washed in PBS once to remove any blood and was immersed in $4 \%$ PFA for $2 \mathrm{~h}$ at $4{ }^{\circ} \mathrm{C}$. The tissue was washed with PBS once to remove PFA and transferred to $30 \%$ sucrose prepared in PBS and kept overnight. The eye was embedded in OCT medium, and 8- $\mu \mathrm{m}$-thick cryo-sections were obtained on poly-L-lysine-coated slides. The tissue sections were fixed using 4\% PFA for $15 \mathrm{~min}$ at RT followed by $3 \mathrm{X}$ washes with PBS for $5 \mathrm{~min}$ each. The sections were then permeabilized for $45 \mathrm{~min}$ at RT with saponin-based buffer and blocked in 5\% BSA solution for 30-45 min at RT followed by 2 washes for $10 \mathrm{~min}$ each. Primary antibodies were added to sections at appropriate dilutions and incubated overnight followed by secondary antibody incubation for $40 \mathrm{~min}$ (1:500 dilution). The nuclei were stained by DAPI at a dilution of $1: 500$ for $5 \mathrm{~min}$, and slides were washed with PBS before mounting the slides using Vectashield. The representative confocal images were taken at $\times 63$ magnification using a system incorporated in the microscope (Zeiss LSM Version 4.2.0.121). Details of primary antibodies used can be found in Supplementary data file Table 1.

\section{Behavioural analysis}

Different groups of animals were analysed for behavioural changes before and after transplantation of RNLCs by visual cliff test, light/dark latency test and optokinetic response test. Detailed methods are given in the Supplementary data file.

\section{Statistical analysis}

All statistical analysis was performed using one way or two way ANOVA post hoc Bonferroni tests. Prior to analysis, data were tested for normality and equal variance using descriptive statistics to ensure that ANOVA assumptions were met. Multi-parametric comparisons between groups were tested with two tailed $t$ tests. $P$ values were corrected for multiple testing if multiple comparisons were performed. $P$ values less than 0.05 were considered significant.

\section{Results}

Reconditioned monocytes exhibit pluripotency and proliferation

The CD $14^{+}$monocytes obtained from PBMCs by enrichment on plastic tissue culture flasks and flow cytometric sorting exhibited a purity of $54.5 \pm 9.39 \%$ and $75.5 \pm$ $6.24 \%$ respectively (Fig. 1a (i, ii)). These cells were 


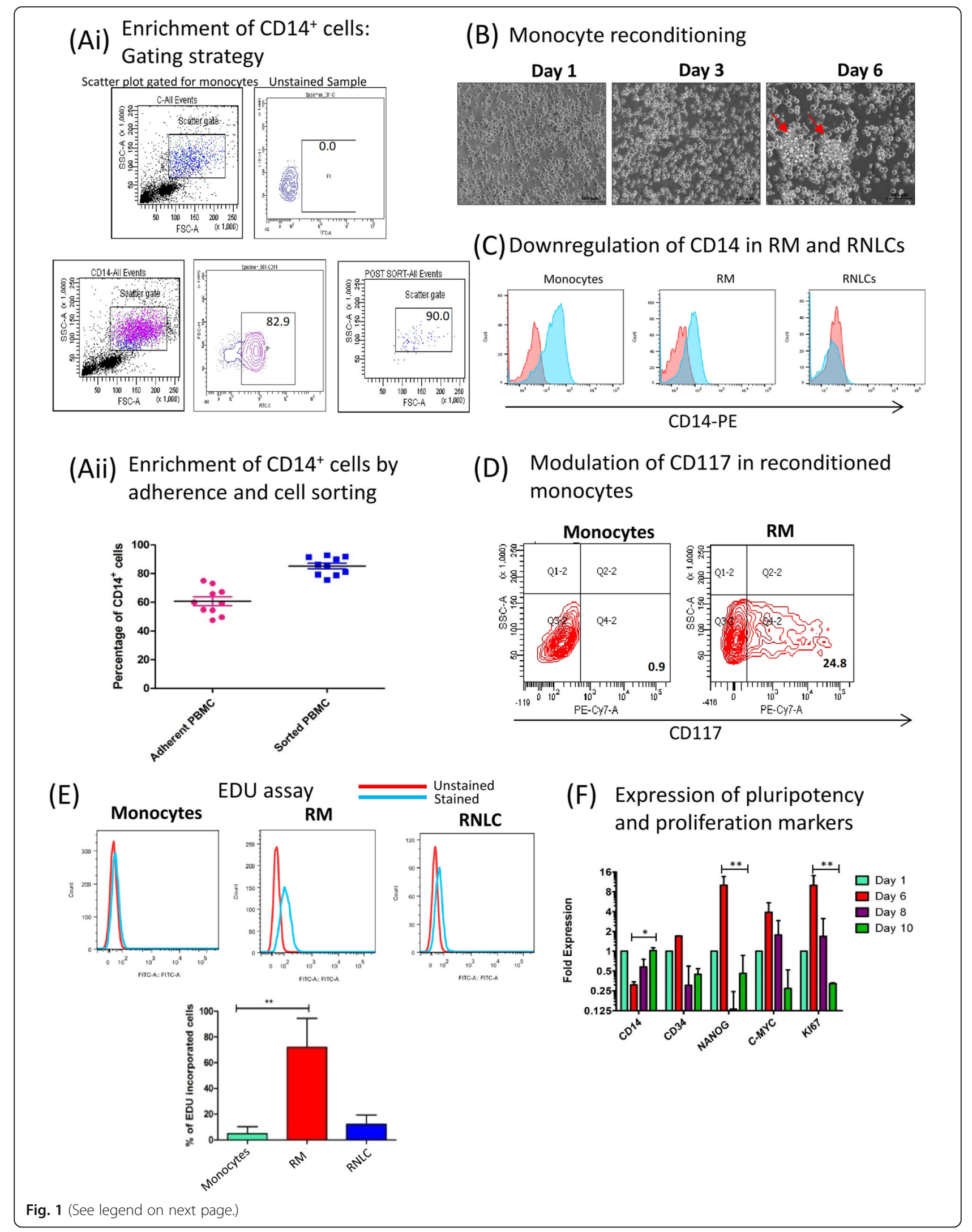


(See figure on previous page.)

Fig. 1 Isolation, recondition and characterization of PBMC derived monocytes into RM. a (i) PBMCs were isolated by density gradient centrifugation method, wherein the buffy coat was diluted in RPMI-1640 media (1:3) which was layered over ficoll. The obtained PBMCs were plated overnight. Thereafter, the non-adherent cells were discarded and the adherent monocyte cells were isolated by trypsinization. The monocytes isolated based on adherence showed reduced purity (65.9\%) as seen by flow cytometric analysis of CD14+ cells gated in side scatter plot. a (ii) Graphical representation of adherent and sorted CD14 $4^{+}$monocyte population showing higher percentage of CD $14^{+}$cells in sorted culture than adherent culture. Around $54.5 \pm 9.39 \%$ cells of adherent PBMCs stained positive for CD14 and $79.5 \pm 6.24 \%$ cells in FACS sorted population were CD14 positive, $(n=10)$. b Bright field images at $\times 20$ resolution showing kinetics of monocyte recondition and morphology alteration. The small round monocytes at day 1 formed colonies and became large and rounded at day 6 (known as reconditioned monocytes or RM). c Flow cytometric analysis of CD14, a monocyte-specific marker, was downregulated in RM and RNLCs and d CD117 was upregulated in RM as compared to monocytes suggesting molecular and phenotypic changes. e 5-Ethynyl-2'-deoxyuridine (EDU) assay was performed to analyse the proportion of proliferative cells. RM showed significant proliferation capacity as against negligible proliferation in monocytes and sparse proliferation in RNLCs. A graphical representation of the EDU analysis is also shown $(n=5)$. $\mathbf{f}$ Kinetic study through qPCR was performed to analyse the pluripotency and proliferation in RM which indicated that RM had a transient expression marker responsible for pluripotency (CD34, NANOG, c-myc) and proliferation markers (KI67) and the stem cell-like properties peaked at day 6 which declined further $(n=5)$. ${ }^{*} p<0.05$; ${ }^{* *} p<0.01 ;{ }^{* * *} p<0.001$

differentiated into reconditioned monocytes (RM) by culturing them in media consisting IL-3, MCSF and $\beta$ $\mathrm{ME}$ in a low serum environment as reported earlier [17]. The monocytes upon de-differentiation became larger in size, rounded and formed colonies by day 6 in culture (Fig. 1b). Flow cytometric and qPCR studies suggested a downregulation of CD14 expression in RM (Fig. 1c) and $25 \%$ increase in the expression of CD117 compared to $0.9 \%$ in day 1 monocytes (Fig. 1d). RM cells (72.06 \pm $18.34 \%$ ) incorporated AF-488 tagged EDU, a thymidine analogue suggesting their active proliferation stage (Fig. $1 \mathrm{e})$ which is absent in terminally differentiated monocytes. We also observed that the expression of $\operatorname{Ki67}(p<$ 0.001), CD34, Nanog $(p<0.001)$ and $c-m y c$ is highest at day 6 followed by a decrease in their expression by day 10 , suggesting that proliferative nature of RM is transient. CD14 expression $(p<0.05)$ also decreases at day 6 during de-differentiation but is elevated back at day 10 in de-differentiation culture (Fig. 1f).

We analysed the expression of myeloid and ectodermal markers in RM as compared to monocytes. Monocyte is a cell type of myeloid cellular origin, and therefore, we wanted to determine if the reconditioned monocytes differed in their lineage marker expression. We found that RM exhibited significant elevation in Pax2 expression while there was no statistical difference in levels of PAX6, OTX2, TUBB, BFGF, CHRD, FOXJ3 and SOX2 (Fig. 2a). The expression of myeloid lineage genes including CD53, CX3CR1, CX3CR6, CD45, CD97, CD11b, CD56 and CD92 was significantly downregulated in RM (Fig. 2b).

\section{Induction with retinal cell differentiation-related extrinsic growth factors causes morphological alteration and retinal marker expression in RM}

Subsequently, RM were cultured in a cocktail of growth factors (IGF-1, bFGF, SCF, RA, EGF, B-27 supplement, MEM-NEAA, ITS (Insulin-Transferrin-Selenium) supplement and $0.5 \%$ ESC grade serum) for 8 days to induce them towards a retinal neuron lineage. The RNLCs, obtained at the end of culture, were composite and exhibited a myriad of morphologies as confirmed by bright field images and SEM analysis (Fig. 2c, d). RNLCs were also capable of cell-cell contacts in vitro through cell extensions (Fig. 2e). The yield of RNLCs obtained at the end of culture term was around $40.5 \pm 11.03 \%$ as indicated by MTT analysis (Fig. 2f).

We analysed PAX-6 expression in RNLCs by western blotting, ICC and flow cytometry. Around $83.2 \pm 7.65 \%$ of RNLCs were PAX-6 positive (Fig. 3a), and we also found expression of $P A X-6$ at protein levels (Fig. 3a). The 'null' expression of $P A X-6$ on monocytes is depicted in supplementary Fig. 1, supplementary data. qPCR analysis indicated a significant upregulation in Recoverin (RCVRN) and IRBP mRNA levels and Rhodopsin protein level (Fig. 3b, c). It appears that the growth factors involved in differentiation of progenitor cells to photoreceptors (PR) for induction of RM towards retinal lineage might have induced the expression of PR markers in reconditioned monocytes (Supplementary Fig. 2).

Flow cytometric analysis of RNLCs stained with $\mathrm{DiBAC}_{4}(3)$ exhibited an increase in fluorescent population in dark adapted RNLCs against a highly reduced fluorescent population in light exposed RNLCs at both time points ( $15 \mathrm{~min}$ and $30 \mathrm{~min}) . \mathrm{DiBAC}_{4}(3)$ dye is a bisoxonol dye that shows increased fluorescence upon depolarization and vice versa. However, RM cells exhibited no significant change between dark-adapted and light-exposed cells treated with the dye as compared to only dye treated control (Fig. 3d).

\section{RNLCs secrete neuroprotective signalling molecules in vitro}

We analysed the secretion of neuroprotective paracrine signalling molecules and neurotransmitters including LGlutamate, acetylcholine and nitric oxide (NO). These molecules are responsible for neuronal circuitry establishment in retina as well as cell-cell interactions. The 
(A) Ectodermal markers expression on RM

(B) Myeloid markers expression on RM
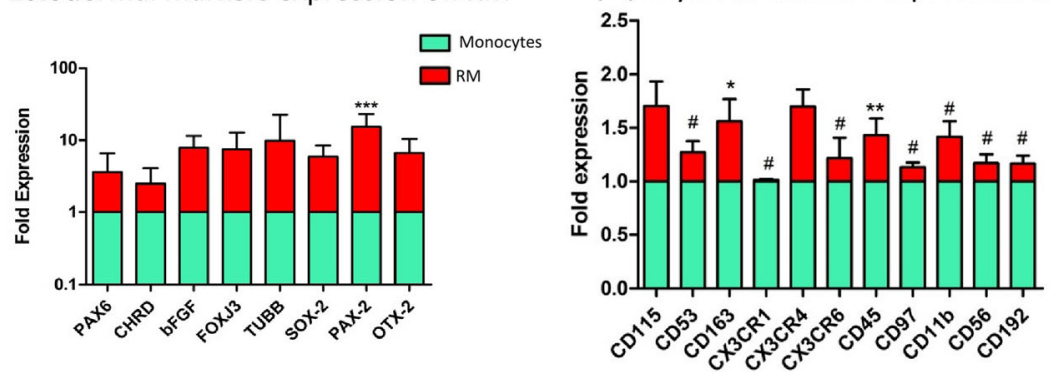

(C) Morphological changes observed in RNLCs Day 8 Day 12

Day 14

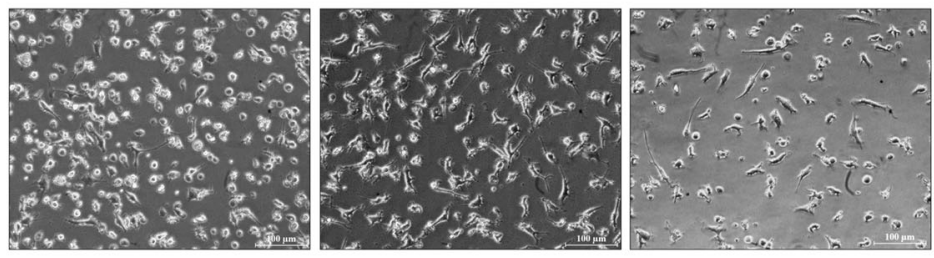

(D) Changes in cell morphology and mixed morphology of neuron like cells
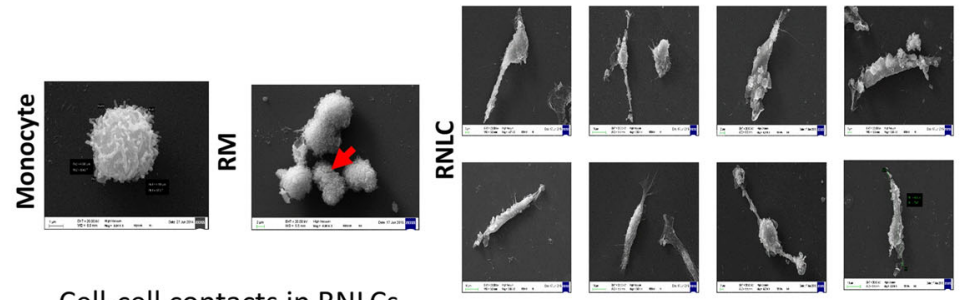

(E)

Cell-cell contacts in RNLCs
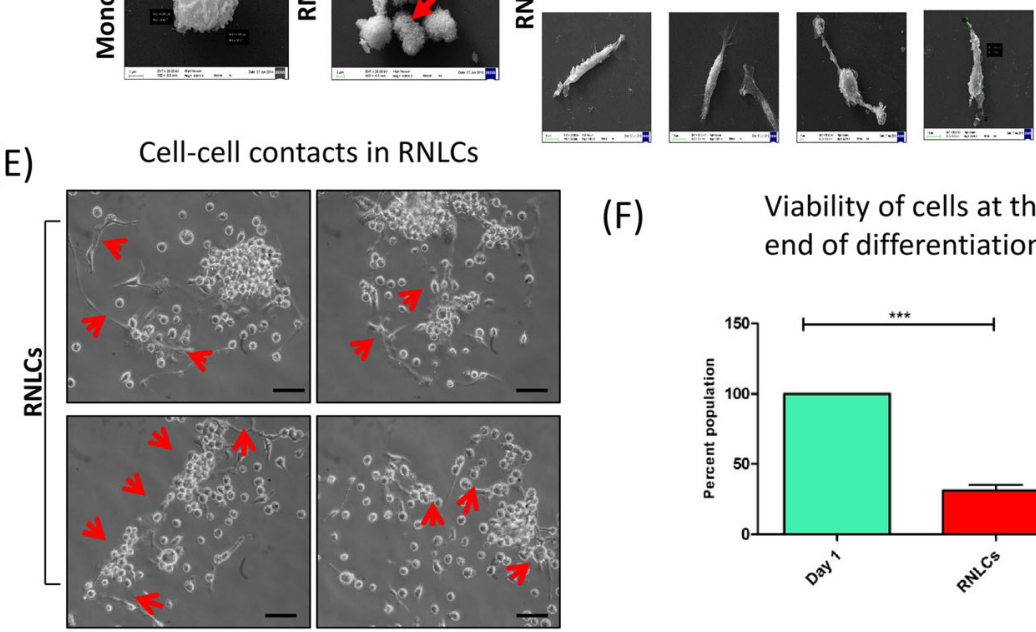

(F)

Viability of cells at the end of differentiation

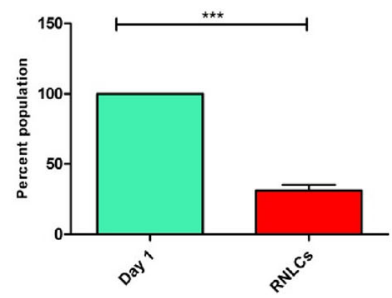

Fig. 2 Characterization of lineage switch in reconditioned monocytes (RM) and their in vitro induction into retinal neuron-like cells (RNLCs). a Ectodermal markers were upregulated as compared to day 1 monocytes. b RM also contributed to express myeloid lineage markers ( $n=4)$. $\mathbf{c}$ Morphology changes observed at $\times 20$ upon induction with extrinsic retinal differentiation growth factors, where round and colony-forming RM formed long, elongated, round and axonal cells which we termed as retinal neuron-like cells (RNLCs) at day 14. d SEM images depicting a typical monocyte which further changes to dividing RM (indicated by red arrow) and eventually to RNLCs exhibiting mixed morphology of neuron-like cells. e The RNLCs also exhibited cell-cell contacts as indicated by red arrows. $\mathbf{f}$ Approximately $40 \%$ cells of the initial PBMCs were live and viable after induction at the culture endpoint as indicated by MTT assay

expression levels of L-glutamate and Ach upregulated significantly at day 8 of RNLC stage as compared to RM at different time points (day 3 and day 6 of RM). Y-79 cell line was used as a positive control (Sup Fig. 4A, B). $\mathrm{NO}$ concentration also elevated at both day 4 and day 8 of RNLC differentiation culture (Sup Fig. 4C).
RNLCs integrate into INL and GCL of immune compromised rd1 retina

CFSE-labelled RNLCs $\left(1 \times 10^{6}\right)$ were initially transplanted retro-orbitally or subretinally in 4-6-week-old NOD.SCID-rd1 mice $(n=2)$ to optimize the route of injection for better engraftment. Post transplantation 
(A) Analysis of PAX-6 expression in RNLCs

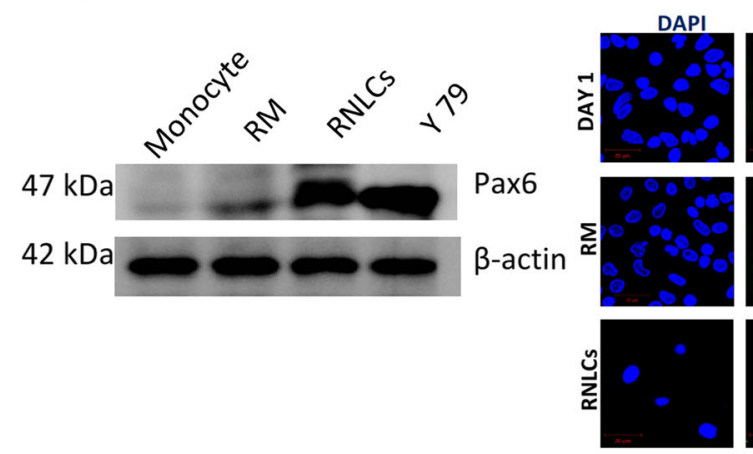

(B) Expression of retinal and neuronal markers

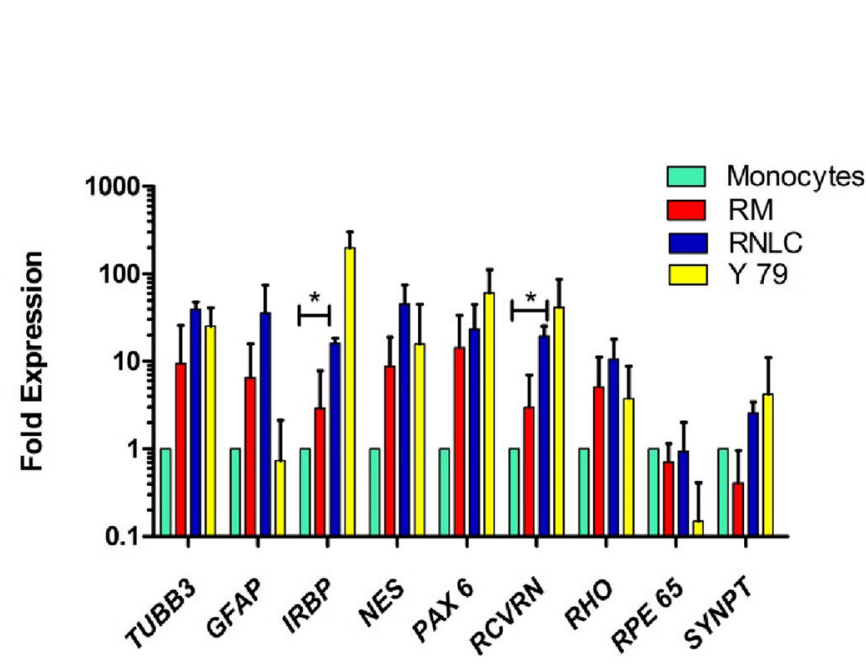

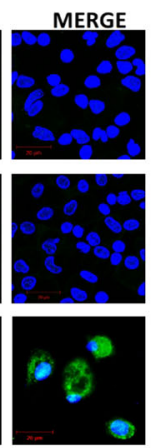
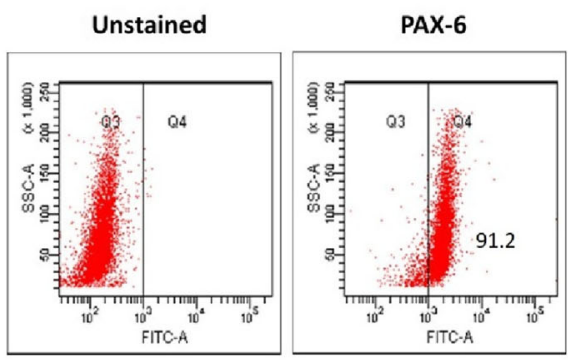

(C) Expression of Rhodopsin on RNLCS
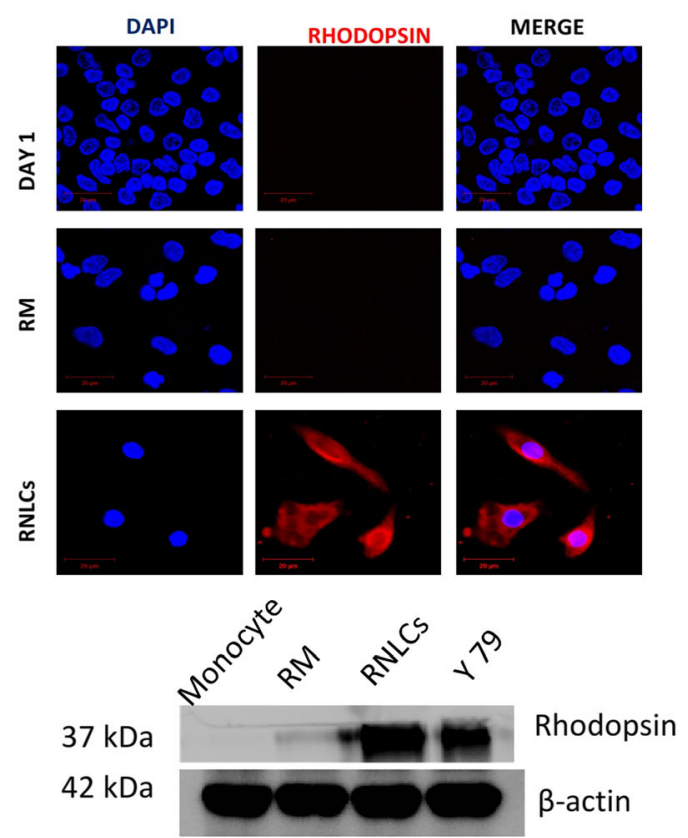

(D) Potentiometric analysis using $\operatorname{DiBAC}_{4}(3)$ dye to identify changes in the membrane potential
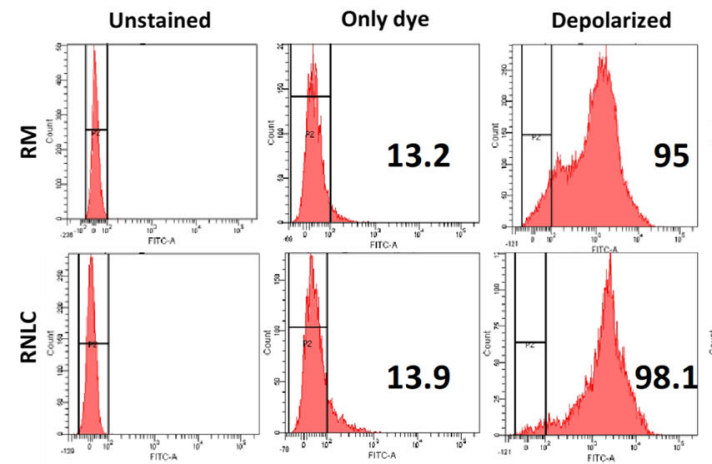

8.1
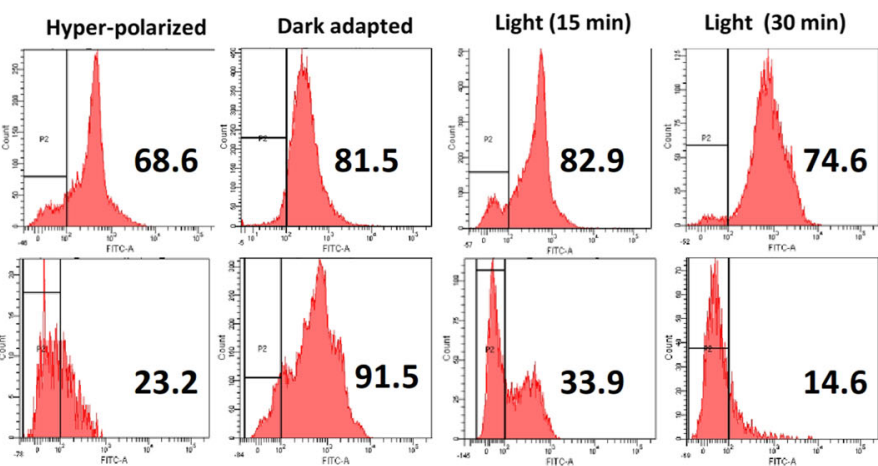

33.9

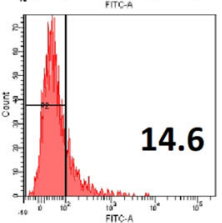

Fig. 3 (See legend on next page.) 


\section{(See figure on previous page.)}

Fig. 3 Characterization of ectodermal and neuronal properties of in vitro induced RNLCs. a PAX-6, an ectodermal and a pan-neuronal/retinal markers, showed expression in RNLCS as shown by both western blotting and ICC, and flow cytometric analysis suggested that around $90 \%$ of the RNLCs were PAX-6 positive. The expression was analysed by flow cytometry, western blotting and ICC. $\mathbf{b}$ qPCR analysis of retinal markers in RNLCs, RM and retinoblastoma cell line Y79 (positive control) $(n=5) .{ }^{*} p<0.05 ;{ }^{* *} p<0.01$. c RNLCs expressed Rhodopsin indicating that these cells had an induced retinal neuron-like properties. The images were captured at $\times 63$ magnification. The western blot analysis also confirmed that RNLCs expressed Rhodopsin after retinal growth factor induction. $\mathbf{d}$ Potentiometric analysis for the changes in membrane potential during light and dark conditions were analysed by using DiBAC4(3) dye. An only dye-treated control was an auto-fluorescence control. Cells treated with valinomycin and gramicidin-D were used as depolarization (DP) and hyperpolarization (HP) controls. The changes in fluorescent intensity were monitored when the cells where dark-adapted and light-exposed for $15 \mathrm{~min}$ and $30 \mathrm{~min}$ respectively. It was observed that RM did not exhibit any noticeable change between dark- (81.5\%) and light-exposed (82.9\%) conditions while RNLCs exhibited an increase in fluorescence intensity (depolarization) (91.5\%) in dark conditions and a significant decrease in fluorescence (Hyperpolarization) (33.9\%) when the cells were exposed to light and further hyperpolarized (14.6\%) on continual light exposure

animals were checked for signs of ocular inflammation, and antibiotic eye drops were applied. The transplanted animals were euthanized after 3 days of injection. The retina was isolated and digested using Papain solution $(10 \mu \mathrm{g} / \mathrm{ml})$ to obtain single cell suspension. We found that approximately $6.19 \%$ RNLCs engrafted in retina upon subretinal and $4.21 \%$ engrafted upon retro-orbital injection (Fig. 4a). IHC studies also indicated that the CFSE-labelled RNLCs engrafted in the outer layers of INL after $48 \mathrm{~h}$ of transplantation in immune-deficient rd1 retina (Fig. 4b). The retina of transplanted mice also labelled positive for human-specific chromosome X suggesting that RNLCs derived from human monocytes could integrate and survive into degenerated rodent retina (Fig. 4c) as seen by FISH analysis. However, qPCR analysis using TaqMan probe specific for human GAPD $\mathrm{H}$ suggested that only $1.25 \pm 0.447 \%(n=5)$ of transplanted cells survived. Ten days after injection (Fig. 4d), the transplanted retina were analysed and it was found that the cells had integrated into mostly in INL and occasionally in GCL, and expressed retinal markers ( $S$ OPSIN, VSX2, GFAP, RCVRN and PDE6b) (Fig. 4e). As a negative control, monocytes were transplanted and processed in an exactly similar manner and sections were stained for S-OPSIN, RCVRN and PDE6b. These sections were 'clear' and no stain was observed. Images are shown in supplementary Fig. 3, supplementary data file.

\section{cGMP levels decrease in both the eye and serum of transplanted animals}

Since Pde6b mutated rd1 animals lack in the function of c-GMP hydrolysis during photo transduction cascade, we checked the cGMP levels in mouse serum and eye lysate samples in non-transplanted and transplanted animals. We found a decreased serum concentration of cGMP in transplanted animals after 10 days as compared to non-transplanted animals (Fig. 5a). BALB/c wild type mice served as positive control. The c-GMP level in eye lysate also reduced in transplanted animals. This might be due to intracellular calcium level changes after transplantation, which alters the saturated cGMP channels by reopening them to function under light adaptations [22]. cGMP levels could also have been modulated by the transplanted RNLCs owing to their monocytic origin. The monocytes release antioxidants which can reduce hypoxia and lower cGMP levels as reported earlier [23].

\section{Macrophage and monocyte expression are upregulated in transplanted retina}

Immune cells like macrophages, NK cells and neutrophils infiltrate the retina during retinal degeneration and inflammatory cytokines flare up causing inflammation [24-26]. Therefore, we studied the changes in immune cell population and inflammatory cytokines in the transplanted retina after 30 days to analyse the inflammatory responses in the retina after transplantation. We found a considerable increase in the levels of anti-inflammatory cytokine IL10 and IL7 and PEDF growth factor in the retina after transplantation; however, we also observed an elevation in the level of macrophage-related markers (MAC1 and CD14). Upregulation in macrophage markers indicates an immune activation response to RNLC transplantation and may play a major role in elimination of transplanted cells over time. We did not find any changes in $\mathrm{T}$ cell marker (CCL2), neutrophils (ly6G) and NK cell marker levels. (Fig. 5b).

\section{Behavioural studies post transplantation}

The transplanted animals were studied for behavioural changes after transplantation, and traits like depth perception, optokinetic response, exploratory behaviour and light latency were examined. We observed that transplanted mice showed marked improved depth perception as evident by their capability to step on shallow side more number of times than deep side in both light (200 lx) and dark conditions (50 lx) $(p<0.05)$ (Fig. 6a, b). The transplanted animals also exhibited a better exploratory behaviour as they were able to locate the opening to the dark chamber easily and showed high number of transitions than non-transplanted mice $(P<0.05)$ (Fig. 6c). Nevertheless, their aversion to light still remained nonconclusive as they spent almost equal time in both the 


\section{(A) Transplantation of RNLCs \\ (B) Engraftment of CFSE labelled RNLC in retina}

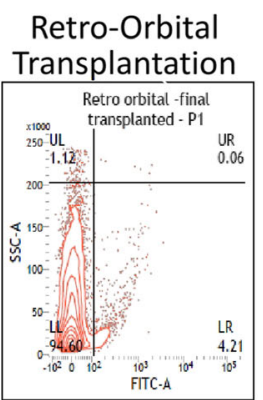

Sub-Retinal

Transplantation

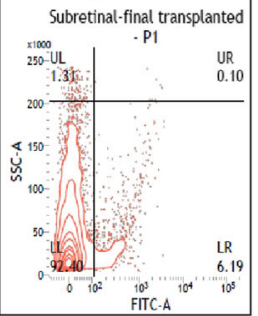

DAPI

RNLC(CFSE labeled)

MERGE
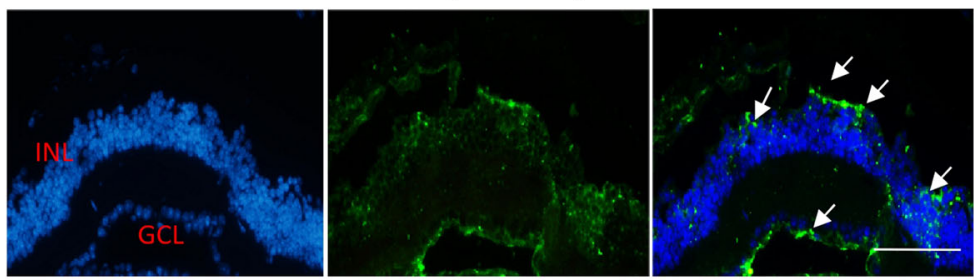

(C)

\section{Engraftment of human}

RNLCs in mouse retina

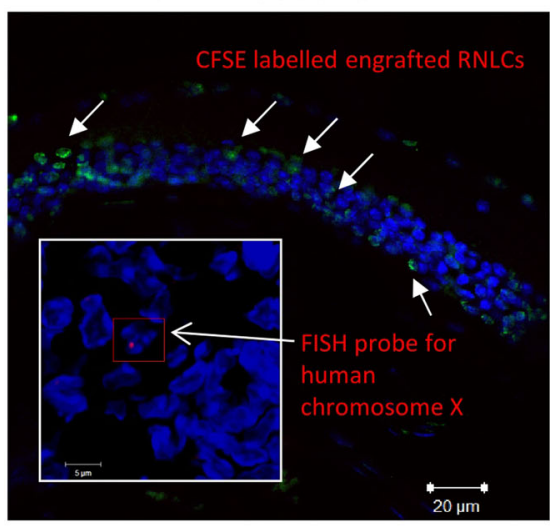

(D) Quantification of engrafted and surviving RNLCs in retina at day 30

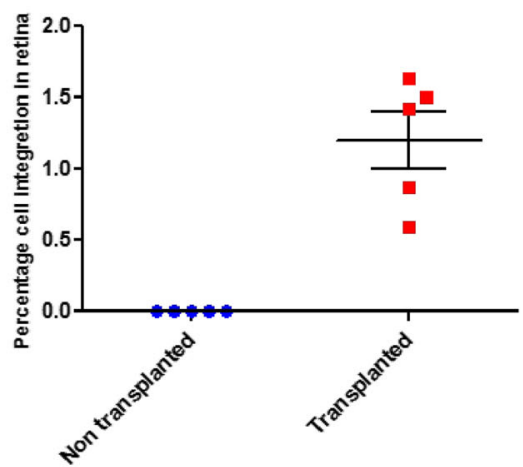

(E) Human specific retinal marker at retina 10 days post transplantation

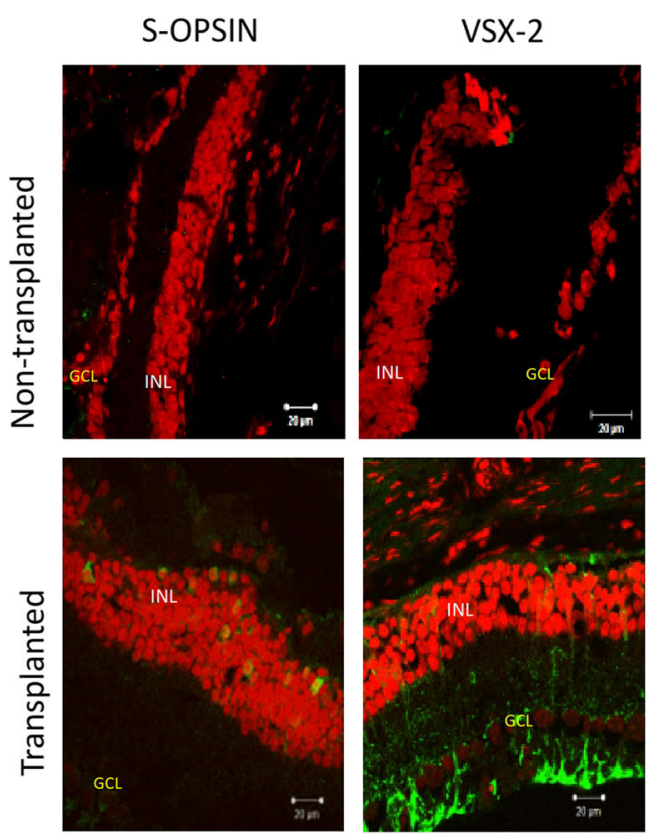

PDE6b

RECOVERIN
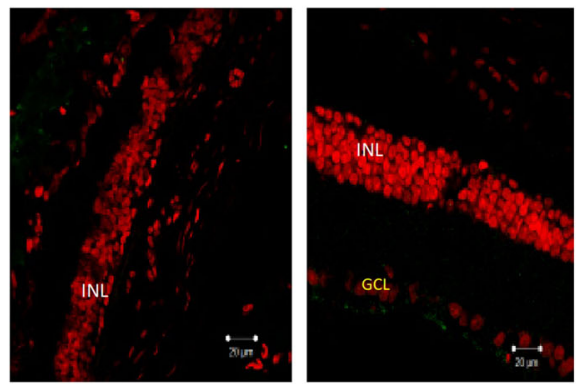

NRL
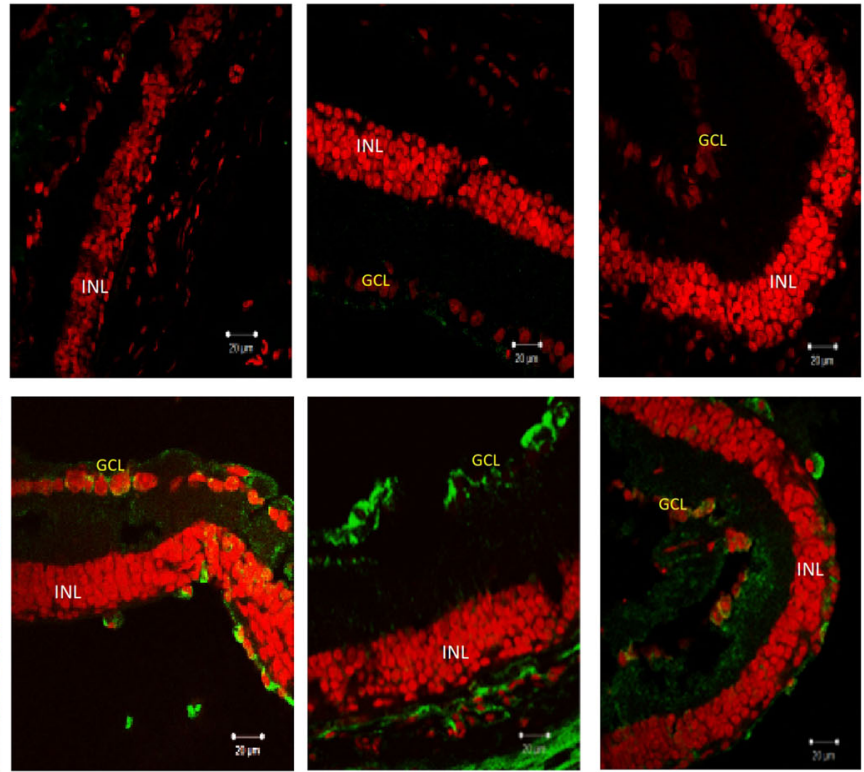

Fig. 4 (See legend on next page.) 
(See figure on previous page.)

Fig. 4 RNLC integration in immune compromised rd1mouse retina and further characterization. a The transplantation of RNLCs into the degenerated retina was optimized via subretinal injection as it offered higher transplantation efficiency (6.19\% RNLCs in retina) than retro-orbital (4.21\% RNLCs in retina as seen by flow cytometric analysis of CFSE-labelled human RNLCs cells gated in side scatter plot vs FITC. $\mathbf{b}$ The CFSElabelled RNLCs could be visualized engrafted in the inner nuclear layer in rd1 retina stained with DAPI which further (c) labelled positive for human specific chromosome X using FISH probe. $\mathbf{d}$ qPCR was performed using GAPDH TaqMan probe to quantify the engrafted RNLCs. Around $1.2 \%$ of human cells were found to survive in the recipient mouse retina after 4 weeks of transplantation $(n=5)$. e $I H C$ was performed for humanspecific retinal markers in the retina of 10 days post transplanted animals. S-OPSIN-, PDE6b-, RCVRN- and NRL-positive cells were found in upper strata of INL while VSX-2-positive cells spanned across INL to GCL. Nuclei: PI (red), respective antibodies: Alexa fluor 488 (green)

chambers and showed no significant improvement (Fig. 6d). We also observed a better response of transplanted animals to head tracking assessment in scotopic conditions (50 lx) at 0.03 cycles per degree (cpd) and $0.13 \mathrm{cpd}$ (Fig. 6e). The changes between transplanted and non-transplanted animals at 0.03 cpd were significant $(p<0.0001)$.

\section{Discussion}

In the present study, we used a two-step approach where human peripheral blood-derived monocytes were induced into RM and then differentiated with retinal growth factors towards neuronal cell type. Monocytes were reconditioned in culture conditions containing growth factors IL3 and MCSF and reducing agents like $\beta-M E$ in a low serum environment for 6 days, initially demonstrated by Zhao et al. [27] and further studied extensively by Ruhnke et al. [19]. MCSF facilitates proliferation and differentiation of monocytes and IL3 is known to lead differentiation and self-renewal of pluripotent stem cells in presence of $\beta-\mathrm{ME}$ and low serum. Thus, this milieu induces pluripotency in monocytes. RM can be identified in culture as large adherent round cell population, sometimes forming colony structures, and are proliferative in nature.

The RM exhibited pluripotency markers like CD34, CD117, OCT-4, SOX-2 and NANOG peaking at day 6 of de-differentiation. CD117 or C-KIT is the gene encoding the receptor tyrosine kinase (stem cell growth factor receptor) which is expressed on the surface of stem cells. CD34 is a progenitor cell marker while OCT-4, SOX-2 and NANOG are transcription factors essential to maintaining the pluripotent embryonic stem cell phenotype [28]. Significant KI67 mRNA expression and incorporation of 5-ethynyl-2' -deoxyuridine (EDU) indicated pluripotency and proliferative capacity of RM. We also observed that the pluripotency in RM was transient and tends to decrease after day 6 . The retrogression in the myeloid lineage observed in RM can be a function of reversible induction of cell cycle regulatory genes or epigenetic changes [29] such as methylation status of CSF$\mathrm{R}$ responsible for de-differentiation [30, 31] and allow lineage-shift [32, 33]. However, the reconditioning of monocytes in this study does not involve manipulation of genes, rather is induced by extrinsic growth factor environment.

The induction of RM into RNLCs was achieved by treating them with a cocktail of growth factors involved in retinal cell differentiation [3]. Growth factors like bFGF [3, 34] and EGF [35] are potent inducers of neuronal phenotype during cell cycle or immediately thereafter. Reports indicate that b-FGF especially induces the early response genes of retinal differentiation [34]. Retinoic acid and taurine play a crucial role in photoreceptor fate determination and differentiation [36-38]. Literature also suggests that IGF-1 and SCF signalling play a major role in the formation of three-dimensional ocular structures from human ESCs and its absence dramatically reduced the level of retinal progenitor genes [32, 38]. Mellough et al. have shown that B27 is a serum free supplement with various factors that assists differentiation of pluripotent cells to photoreceptors [38].

Upon induction for a period of 8 days, RNLCs exhibited morphological alteration showing elongated structure, neuron-like axonal spread out and cell-cell contacts. Additionally, we found a significant upregulation in neuro-signalling molecules like L-glutamate, Ach and NO that also act as paracrine factors in retina and facilitate cell interactions [39-41]. qPCR results showed that RNLCs also exhibited an upregulation in a few neuronal and retinal markers (IRBP and RHO mRNA). RNLCs expressed retinal markers PAX-6 and RHO at protein levels. Approximately $90 \%$ of RNLC population was PAX-6+ve suggesting that a large proportion of RM shifted towards ectodermal neuronal lineage which correlates to previous study by Kodama et al. [42] who demonstrated the capacity of monocyte-derived multipotential cells (MOMC) to differentiate into neuroectodermal lineages suggesting that circulating CD14+ monocytes are highly multipotential.

The RNLCs also demonstrated membrane potential changes during light and dark adaptations as measured by changes in DiBAC4(3) fluorescence intensity which was largely a relative comparison between RM and RNLC $[43,44]$. It has been reported earlier that bisoxonol dyes may sometimes show artefacts and lower temporal resolution in measurement of membrane potential [45] and that the demonstration of fluorescence 
(A) Analysis of cGMP levels in retina and serum of transplanted mice

Serum

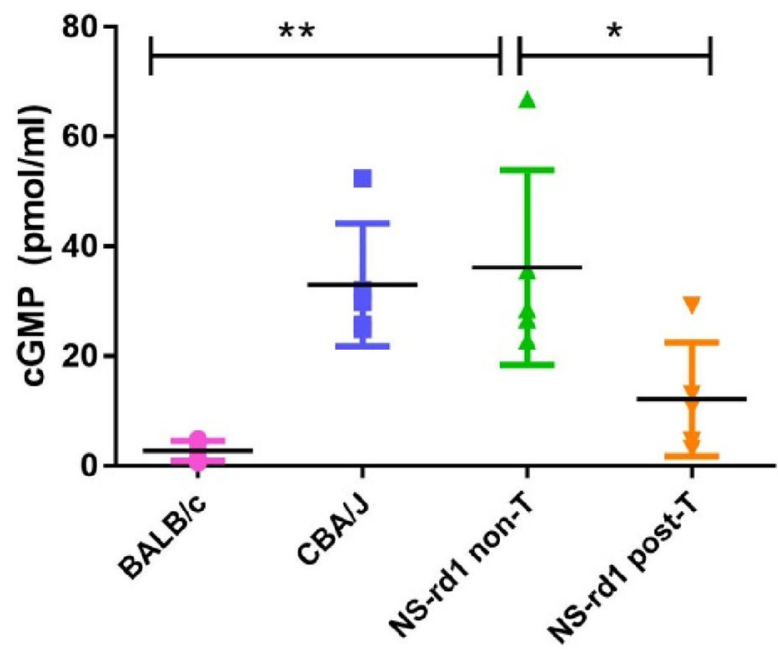

(B) Expression of inflammatory markers

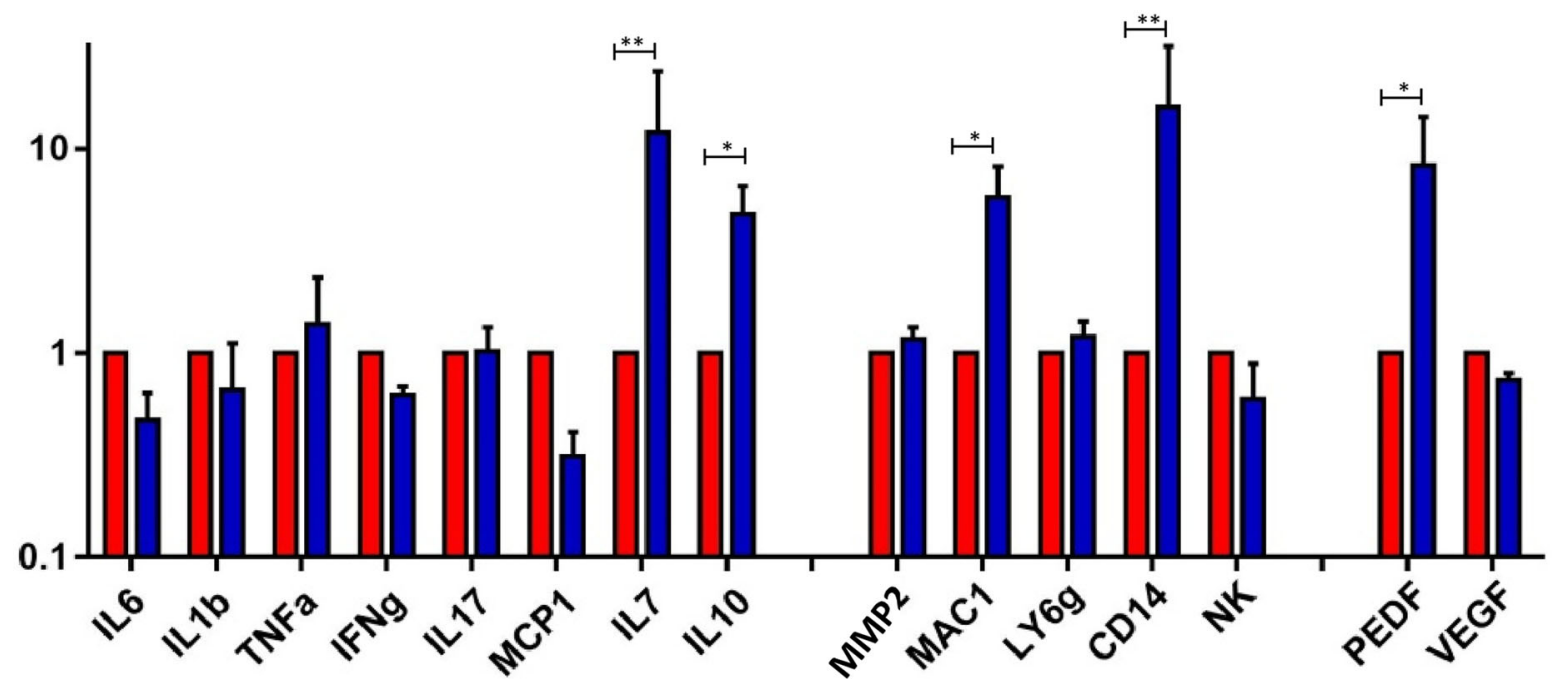

Fig. 5 Analysis of transplanted animals for cGMP levels and inflammatory markers. a The serum level of cGMP was significantly reduced in post transplanted animals eye lysate samples also exhibited a slight reduction in total cGMP content post transplantation. (wild type) BALB/c, (rd1 model) CBA/J, transplanted animals (NOD-SCID-rd1). b qPCR analysis in transplanted animals suggested that pro-inflammatory cytokines such as TNF-a while anti-inflammatory cytokines such as IL-7 and IL-10 were exacerbated. The expression of MAC-1- and CD14-positive cells were upregulated while NK, (T cells) CCL2 and (Neutrophils) Ly6G had no noticeable difference. PEDF, a neuroprotective growth factor, was upregulated while VEGF showed no change $(n=4)$

intensity changes in DiBAC4(3) associated with membrane potential is largely relative rather than quantitative in our current study.

Transplantation of RNLCs in immune compromised NOD.SCID-rd1 mice via trans-corneal sub-retinal transplantation resulted in their engraftment owing to proximity between damaged layer and site of transplanted cells [2] and that it is more immune privileged than other retinal regions [46]. As previously shown in our lab and by other groups, the cell engraftment efficiency in an immune-deficient rd1 model is higher than an immune-competent $\mathrm{rd} 1$ 


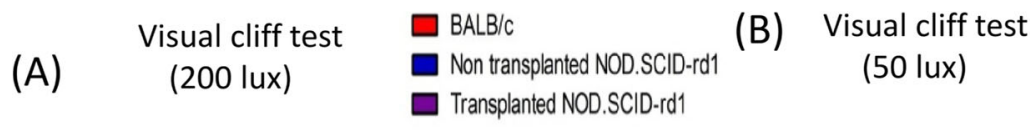
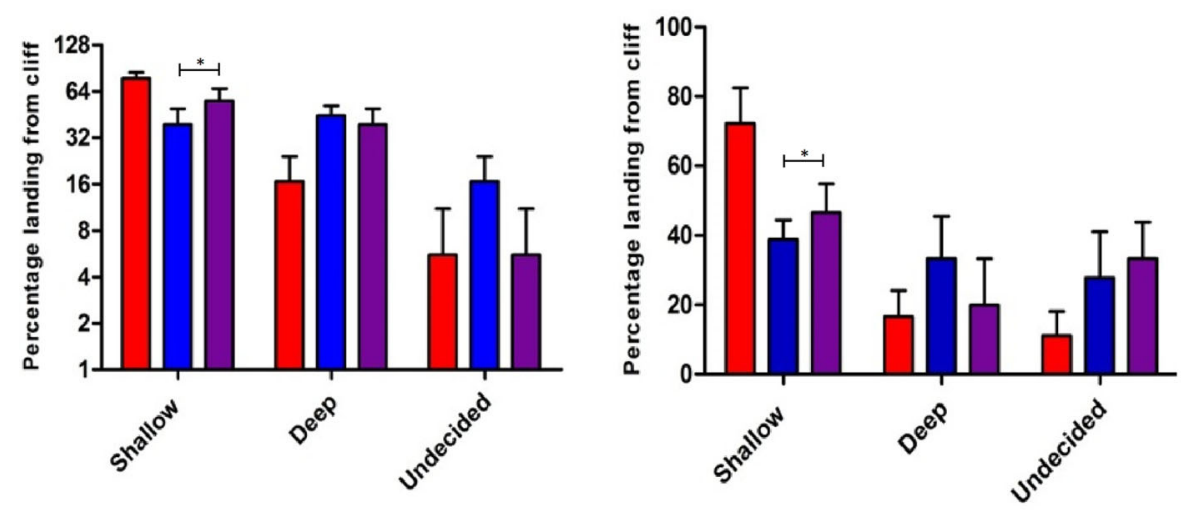

(C) Light/dark latency test

(D)

Light/dark latency test
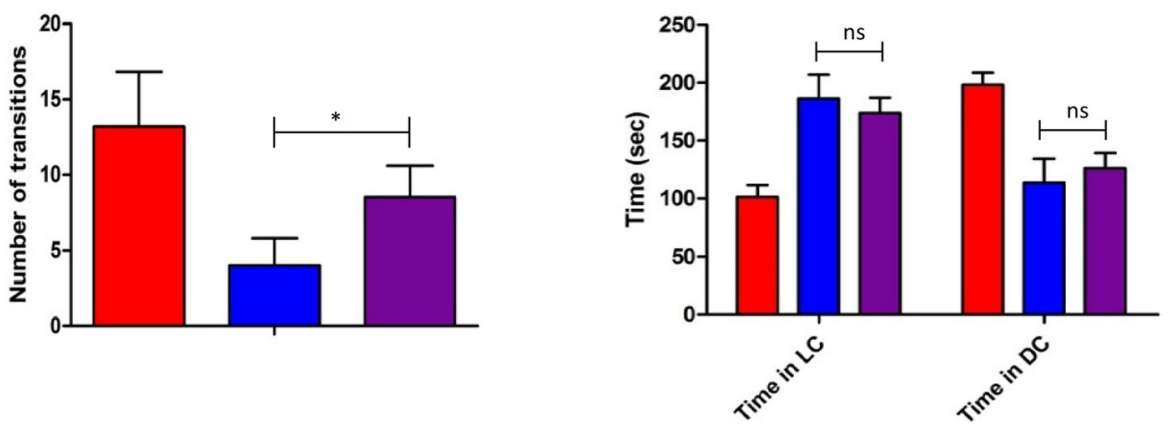

(E) Opto-kinetic response

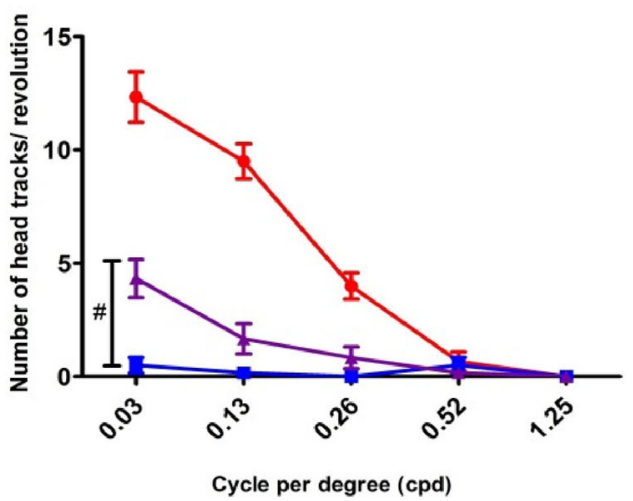

Fig. 6 Functional analysis for vision rescue in host after transplantation of RNLCs in the retina. a The transplanted mice showed improved depth perception and stepped on the shallow side more number of times than deep side in both light (200 Ix) and $\mathbf{b} \operatorname{dim}(50 \mathrm{~lx})$ conditions. c The light/dark latency test suggested that the transplanted animals spent comparable time in light chamber and that there was no noticeable change in their aversion to light as compared to non-transplanted animals. $\mathbf{d}$ The transplanted mice had an increased exploratory behaviour indicated by transitions between light chamber (LC) and dark chamber (DC) $(n=6)$. e The transplanted mice displayed significant increase in head tracks at 0.03 cycles per degree (cpd). It exhibited no significant change for the rest of the spatial frequencies $(n=6)$; ${ }^{*} p<0.05$; \#p $<0.001$

model [20, 47, 48]. Therefore, we performed cell transplantation studies on immunodeficient $\mathrm{rd} 1$ mouse model to assess cell integration.
Around $1.2 \pm 0.447 \%$ cells of total transplanted CFSElabelled RNLCs survived in the retina after 4 weeks of transplantation. The engrafted RNLCs expressed human- 
specific retinal markers like RCVRN, NRL (early PR markers), VSX2 (Pan-bipolar cell marker), PDE6B (phototransduction marker) and S-OPSIN (cone PR marker) dispersed throughout the INL and GCL. The monocyte transplanted retina however did not show any retinal marker expression. Therefore, we speculate that the in vivo ocular microenvironment helps the already induced RNLCs to integrate and further acquire retinal celllike characteristics after transplantation.

The transplanted animals displayed lower levels of cGMP in both eye lysate as well in serum after 10 days of transplantation. This might be due to intracellular calcium changes altering the saturated cGMP channels. Alternatively, it is known that monocytes release antioxidants which can reduce hypoxia and lower cGMP levels as reported earlier [23]. Therefore, the monocytic origin of induced RNLCs may have caused the lowering of cGMP levels. Immune cells including $M A C-1$ - and CD14-positive cell mRNA (macrophages and monocytes respectively) were increased, suggesting that these inflammatory cells were activated in retina following transplantation. PEDF and IL-10 were also upregulated in transplanted animals indicating the highly active neuroprotection activity in retina after transplantation. The rd1 model used for transplantation was devoid of $\mathrm{B}$ and $\mathrm{T}$ cells and had a reduced NK cell activity (NOD.SCID-rd1). This explains the fact that there was no NK cell activity.

The behavioural changes in transplanted mice indicated that they had improved depth perception in both light and dim conditions as indicated by their ability to step on shallow side of the cliff. The transplanted mice also had an improved exploratory behaviour than nontransplanted animals while their behaviour study showing aversion to light was not conclusive. We also observed significantly improved optokinetic response in the transplanted mice at $0.03 \mathrm{cpd}$. Even though the behavioural changes in the transplanted animals are promising, we speculate that the percentage of transplanted cells $(1.25 \%)$ that engrafted is insufficient for cell-based therapeutic effect and for structural rescue. Previous studies on cell therapy have encountered similar situations where the engraftment of cells is low, but they observed significant therapeutic efficacy, which was attributed to paracrine activity of cells and their capability to secrete neuroprotective cytokines and growth factors $[49,50]$.

In the present study, we have not investigated a direct evidence for the paracrine mechanism upon cell transplantation. However, several cases in our study indirectly point towards elicitation of paracrine effect in the retina upon transplantation of RNLCs. We observe an elevation of IL-10 (an anti-inflammatory cytokine) in retina upon transplantation which suggests immune-protective effect of RNLCs. We also found upregulated PEDF growth factor (involved in anti-angiogenesis and neuroprotective functions for photoreceptor cells and retina) in transplanted retina which points towards involvement of paracrine-based protective role of RNLCs in retina.

We also find that RNLCs have the potential to secrete neurotransmitters like nitric oxide, acetylcholine and Lglutamate in vitro, which also have a broad range of paracrine signalling function in neurons besides synaptic functions [39-41] (Sup Fig. 4).

We speculate that RNLCs act in paracrine fashion and secrete neuronal growth factors which help in sustenance and survival of retinal cells and function in stress conditions. Several groups have previously shown that dedifferentiated monocytes with pluripotent and plastic nature can secrete EGF, TGF- $\beta$ and Activin in vitro [51]. We are also currently studying the underlying mechanisms for therapeutic effect of RNLC transplantation.

Our current findings suggest that monocytes can be reconditioned to elicit pluripotency and proliferation and induced towards neuronal lineage extrinsically. The induced RNLCs have the ability to integrate into retina of immune-deficient rd1 mice. RNLCs can also utilize the retinal microenvironment to supplement their further differentiation and survival into retinal layers and express retinal markers. However, this preliminary study is limited by a small group of animals, and further mechanistic and quantitative functional assessment in a larger number of animals need to be performed to confirm if induced RNLCs could potentially be used for long-term therapeutics in retinal degenerative disorders.

\section{Conclusion}

Monocytes were cultured in a defined medium to create the right environment to elicit their physiological pluripotent capacities. The pluripotent cells of monocyte origin (RM) are adherent, colony forming cell population and exhibit transient pluripotency and proliferation. We induced RM towards a neuronal lineage by culturing them with a cocktail of growth factors involved in retinal cell differentiation. The neuronal induction causes morphological, physiological and molecular alterations in RM, and these cells have reduced expression of monocytic and myeloid markers and upregulated ectodermal and retinal neuron markers. Transplantation of RNLCs in immune compromised NOD.SCID-rd1 mice via trans-corneal subretinal transplantation resulted in their engraftment in INL and GCL. It also led to macrophage/ monocyte upregulation. The transplanted mice demonstrated slightly improved depth perception in both light and dim conditions and a better optokinetic response. In this study, we successfully demonstrated that abundantly accessible peripheral blood-derived monocytes, which are highly abundant and can be obtained by minimal invasive procedures, can be inducted towards neuronal 
lineage. However, we need further studies to explore the functional activity and in vivo differentiation capacity of the induced RNLCs. It would establish monocytederived induced RNLCs as a potential candidate for future cell therapy studies in ocular diseases, and their utilization for disease modelling and drug screening purposes.

\section{Supplementary information}

Supplementary information accompanies this paper at https://doi.org/10. 1186/s13287-020-01925-y.

Additional file 1. Detailed methods and additional data are given in the Supplementary data file.

\section{Abbreviations}

EDU: 5-Ethynyl-2'-deoxyuridine; b-FGF: Basis fibroblast growth factor; CFSE: Carboxyflourescein succinimidyl ester; cpd: Cycles per degree; DP: Depolarization; ESC: Embryonic stem cells; EGF: Epidermal growth factor; FBS: Fetal bovine serum; GCL: Ganglion cell layer; HP: Hyperpolarization; iPSC: Induced pluripotent stem cells; INL: Inner nuclear layer; IGF1: Insulin growth factor 1; IL: Interleukin; MCSF: Macrophage colony-stimulating factor; NK: Natural killer cells; NRL: Neural retina-specific leucine zipper; NEAA: Nonessential amino acid; PFA: Paraformaldehyde; PBMC: Peripheral blood mononuclear cells; PR: Photoreceptors; PEDF: Pigment epithelium-derived factor; PI: Propidium iodide; RM: Reconditioned monocytes; RCVR N: Recoverin; RNLC: Retinal neuron-like cells; RP: Retinitis pigmentosa; RA: Retinoic acid; RHO: Rhodopsin; RT: Room temperature; SCF: Stem cell factor; PDE6B : $\beta$-subunits of phosphodiesterase 6

\section{Acknowledgements}

Rekha Rani for confocal and SEM Microscopy, Vikash Kumar for help with sorting CD14+ monocytes.

\section{Authors' contributions}

Conceptualization and design-AM and PU; collection and/or assembly of data-AM, SI, AK, MN, LM, JB, BD, KJ, PSahu, PSinha, KVM and PU; manuscript writing-AM, AK, KVM and PU; supervision-PN, TV and PU. All authors read and approved final manuscript.

\section{Funding}

This work was supported by the core grant received from the Department of Biotechnology, Government of India to National Institute of Immunology, New Delhi. PSinha is grateful to DBT for research fellowship. The funders had no role in study design, data collection, analysis, decision to publish and preparation of the manuscript.

\section{Availability of data and materials}

All data generated or analysed during this study are included in this published article and its supplementary data file.

\section{Ethics approval and consent to participate}

Ethical clearance was obtained from Institutional Human Ethics Committee of National Institute of Immunology, New Delhi, for procuring buffy coat of healthy blood samples (IHEC\#85/14). Approval to perform animal experiments was obtained from Institutional Animal Ethics Committee of National Institute of Immunology, New Delhi (IAEC\#334/14).

\section{Consent for publication}

Not applicable.

\section{Competing interests}

The authors declare that they have no competing interests.

\section{Author details}

${ }^{1}$ National Institute of Immunology, Aruna Asaf Ali Marg, New Delhi 110067 India. ${ }^{2}$ Department of Ocular Pharmacology, Dr. Rajendra Prasad Centre for
Ophthalmic Sciences, All India Institute of Medical Sciences, New Delhi 110029, India.

Received: 11 June 2020 Revised: 17 August 2020

Accepted: 4 September 2020 Published online: 23 September 2020

\section{References}

1. Francis PJ. Genetics of inherited retinal disease. J R Soc Med. 2006;99(4):18991.

2. Ramsden CM, Powner MB, Carr AJ, Smart MJ, da CL, Coffey PJ. Stem cells in retinal regeneration: past, present and future. Development. 2013;140(12): $2576-2585$

3. Altshuler D, Cepko C. A temporally regulated, diffusible activity is required for rod photoreceptor development in vitro. Development. 1992;114(4):94757.

4. Sahaboglu A, Paquet-Durand O, Dietter J, Dengler K, Bernhard-Kurz S, Ekstrom PA, et al. Retinitis pigmentosa: rapid neurodegeneration is governed by slow cell death mechanisms. Cell Death Dis. 2013;4:e488.

5. Bainbridge JW, Tan MH, Ali RR. Gene therapy progress and prospects: the eye. Gene Ther. 2006;13(16):1191-7.

6. Barnstable CJ, Tombran-Tink J. Molecular mechanisms of neuroprotection in the eye. Adv Exp Med Biol. 2006:572:291-5.

7. Alteheld N, Roessler G, Walter P. Towards the bionic eye--the retina implant: surgical, opthalmological and histopathological perspectives. Acta Neurochir Suppl. 2007;97(Pt 2):487-93.

8. Winter JO, Cogan SF, Rizzo JF III. Retinal prostheses: current challenges and future outlook. J Biomater Sci Polym Ed. 2007;18(8):1031-55.

9. Enzmann V, Yolcu E, Kaplan HJ, Ildstad ST. Stem cells as tools in regenerative therapy for retinal degeneration. Arch Ophthalmol. 2009;127(4): 563-71.

10. Lamba DA, Gust J, Reh TA. Transplantation of human embryonic stem cellderived photoreceptors restores some visual function in Crx-deficient mice. Cell Stem Cell. 2009:4(1):73-9.

11. Di Foggia V, Makwana P, Ali RR, Sowden JC. Induced pluripotent stem cell therapies for degenerative disease of the outer retina: disease modeling and cell replacement. J Ocul Pharmacol Ther. 2016;32(5):240-52.

12. Volarevic V, Markovic BS, Gazdic M, Volarevic A, Jovicic N, Arsenijevic N, et al. Ethical and safety issues of stem cell-based therapy. Int J Med Sci. 2018;15(1):36-45.

13. Urbach A, Bar-Nur O, Daley GQ, Benvenisty N. Differential modeling of fragile $X$ syndrome by human embryonic stem cells and induced pluripotent stem cells. Cell Stem Cell. 2010;6(5):407-11.

14. Pera MF. Stem cells: the dark side of induced pluripotency. Nature. 2011; 471(7336):46-7.

15. Bellon A, Wegener A, Lescallette AR, Valente M, Yang SK, Gardette R, et al. Transdifferentiation of human circulating monocytes into neuronal-like cells in 20 days and without reprograming. Front Mol Neurosci. 2018;11:323.

16. Carcamo-Orive I, Hoffman GE, Cundiff P, Beckmann ND, D'Souza SL, Knowles JW, et al. Analysis of transcriptional variability in a large human iPSC library reveals genetic and non-genetic determinants of heterogeneity. Cell Stem Cell. 2017;20(4):518-32 e9.

17. Fossati $V$, Jain T, Sevilla A. The silver lining of induced pluripotent stem cell variation. Stem Cell Investig. 2016;3:86.

18. Hu BY, Weick JP, Yu J, Ma LX, Zhang XQ, Thomson JA, et al. Neural differentiation of human induced pluripotent stem cells follows developmental principles but with variable potency. Proc Natl Acad Sci U S A. 2010;107(9):4335-40.

19. Ruhnke M, Ungefroren H, Nussler A, Martin F, Brulport M, Schormann W, et al. Differentiation of in vitro-modified human peripheral blood monocytes into hepatocyte-like and pancreatic islet-like cells. Gastroenterology. 2005;128(7):1774-86.

20. Mishra A, Das B, Nath M, lyer S, Kesarwani A, Bhattacharjee J, et al. A novel immunodeficient NOD.SCID-rd1 mouse model of retinitis pigmentosa to investigate potential therapeutics and pathogenesis of retinal degeneration. Biol Open. 2017;6(4):449-62.

21. Kilkenny C, Browne WJ, Cuthill IC, Emerson M, Altman DG. Improving bioscience research reporting: the ARRIVE guidelines for reporting animal research. PLoS Biol. 2010;8(6):e1000412.

22. Coccia VJ, Cote RH. Regulation of intracellular cyclic GMP concentration by light and calcium in electropermeabilized rod photoreceptors. J Gen Physiol. 1994;103(1):67-86. 
23. Pietarinen-Runtti $P$, Lakari E, Raivio KO, Kinnula VL. Expression of antioxidant enzymes in human inflammatory cells. Am J Physiol Cell Physiol. 2000; 278(1):C118-25.

24. Hori J, Vega JL, Masli S. Review of ocular immune privilege in the year 2010: modifying the immune privilege of the eye. Ocul Immunol Inflamm. 2010; 18(5):325-33.

25. Singh MS, Charbel IP, Butler R, Martin C, Lipinski DM, Sekaran S, et al. Reversal of end-stage retinal degeneration and restoration of visual function by photoreceptor transplantation. Proc Natl Acad Sci U S A. 2013;110(3): 1101-6.

26. Whitcup SM, Nussenblatt RB, Lightman SL, Hollander DA. Inflammation in retinal disease. Int J Inflam. 2013;2013:724648.

27. Zhao Y, Glesne D, Huberman E. A human peripheral blood monocytederived subset acts as pluripotent stem cells. Proc Natl Acad Sci U S A. 2003;100(5):2426-31.

28. Hadjimichael C, Chanoumidou K, Papadopoulou N, Arampatzi P, Papamatheakis J, Kretsovali A. Common stemness regulators of embryonic and cancer stem cells. World J Stem Cells. 2015;7(9):1150-84.

29. Hass R, Gunji H, Datta R, Kharbanda S, Hartmann A, Weichselbaum R, et al. Differentiation and retrodifferentiation of human myeloid leukemia cells is associated with reversible induction of cell cycle-regulatory genes. Cancer Res. 1992;52(6):1445-50.

30. Felgner J, Kreipe $H$, Heidorn $K$, Jaquet $K$, Heuss $R$, Zschunke F, et al. Lineagespecific methylation of the $c$-fms gene in blood cells and macrophages. Leukemia. 1992;6(5):420-5.

31. Parwaresch MR, Kreipe H, Felgner J, Heidorn K, Jaquet K, Bodewadt-Radzun $\mathrm{S}$, et al. M-CSF and M-CSF-receptor gene expression in acute myelomonocytic leukemias. Leuk Res. 1990;14(1):27-37.

32. James J, Das AV, Rahnenfuhrer J, Ahmad I. Cellular and molecular characterization of early and late retinal stem cells/progenitors: differential regulation of proliferation and context dependent role of Notch signaling. J Neurobiol. 2004;61(3):359-76.

33. Mummery CL, Feyen A, Freund E, Shen S. Characteristics of embryonic stem cell differentiation: a comparison with two embryonal carcinoma cell lines. Cell Differ Dev. 1990;30(3):195-206.

34. Lillien L, Cepko C. Control of proliferation in the retina: tempora changes in responsiveness to FGF and TGF alpha. Development. 1992; 115(1):253-66.

35. Spencer SA, Powell PA, Miller DT, Cagan RL. Regulation of EGF receptor signaling establishes pattern across the developing Drosophila retina. Development. 1998;125(23):4777-90.

36. Kelley MW, Turner JK, Reh TA. Retinoic acid promotes differentiation of photoreceptors in vitro. Development. 1994;120(8):2091-102.

37. Lake $\mathrm{N}$. Taurine and GABA in the rat retina during postnatal development. Vis Neurosci. 1994;11(2):253-60

38. Mellough CB, Collin J, Khazim M, White K, Sernagor E, Steel DH, et al. IGF-1 signaling plays an important role in the formation of three-dimensional laminated neural retina and other ocular structures from human embryonic stem cells. Stem Cells. 2015;33(8):2416-30.

39. Edwards D, Das M, Molnar P, Hickman JJ. Addition of glutamate to serumfree culture promotes recovery of electrical activity in adult hippocampal neurons in vitro. J Neurosci Methods. 2010;190(2):155-63.

40. Guimaraes C, Assreuy J, Linden R. Paracrine neuroprotective effect of nitric oxide in the developing retina. J Neurochem. 2001;76(4):1233-41.

41. Piccirillo S, Castaldo P, Macri ML, Amoroso S, Magi S. Glutamate as a potential "survival factor" in an in vitro model of neuronal hypoxia/ reoxygenation injury: leading role of the $\mathrm{Na}(+) / \mathrm{Ca}(2+)$ exchanger. Cell Death Dis. 2018;9(7):731.

42. Kodama H, Inoue $T$, Watanabe $R$, Yasutomi D, Kawakami Y, Ogawa S, et al. Neurogenic potential of progenitors derived from human circulating CD14+ monocytes. Immunol Cell Biol. 2006;84(2):209-17.

43. Baylor DA. Photoreceptor signals and vision. Proctor lecture Invest Ophthalmol Vis Sci. 1987;28(1):34-49.

44. Fu Y. Phototransduction in Rods and Cones. In: Kolb H, Fernandez E, Nelson $R$, editors. Webvision: The organization of the retina and visual system. Salt Lake City (UT) 1995

45. Yamada A, Gaja N, Ohya S, Muraki K, Narita H, Ohwada T, et al. Usefulness and limitation of DiBAC4(3), a voltage-sensitive fluorescent dye, for the measurement of membrane potentials regulated by recombinant large conductance Ca2+-activated K+ channels in HEK293 cells. Jpn J Pharmacol. 2001;86(3):342-50
46. Streilein JW, Ma N, Wenkel H, Ng TF, Zamiri P. Immunobiology and privilege of neuronal retina and pigment epithelium transplants. Vis Res. 2002;42(4): 487-95.

47. Zhu J, Cifuentes H, Reynolds J, Lamba DA. Immunosuppression via loss of IL2rgamma enhances long-term functional integration of hESC-derived photoreceptors in the mouse retina. Cell Stem Cell. 2017;20(3):374-84.

48. Seiler MJ, Aramant RB, Jones MK, Ferguson DL, Bryda EC, Keirstead HS. A new immunodeficient pigmented retinal degenerate rat strain to study transplantation of human cells without immunosuppression. Graefes Arch Clin Exp Ophthalmol. 2014;252(7):1079-92.

49. Bakondi B, Girman S, Lu B, Wang S. Multimodal delivery of isogenic mesenchymal stem cells yields synergistic protection from retinal degeneration and vision loss. Stem Cells Transl Med. 2017;6(2):444-57.

50. Cui Y, Xu N, Xu W, Xu G. Mesenchymal stem cells attenuate hydrogen peroxide-induced oxidative stress and enhance neuroprotective effects in retinal ganglion cells. In Vitro Cell Dev Biol Anim. 2017;53(4):328-35.

51. Ungefroren $H$, Hyder A, Schulze M, Fawzy El-Sayed KM, Grage-Griebenow E, Nussler AK, et al. Peripheral blood monocytes as adult stem cells: molecular characterization and improvements in culture conditions to enhance stem cell features and proliferative potential. Stem Cells Int. 2016;2016:7132751.

\section{Publisher's Note}

Springer Nature remains neutral with regard to jurisdictional claims in published maps and institutional affiliations.
Ready to submit your research? Choose BMC and benefit from:

- fast, convenient online submission

- thorough peer review by experienced researchers in your field

- rapid publication on acceptance

- support for research data, including large and complex data types

- gold Open Access which fosters wider collaboration and increased citations

- maximum visibility for your research: over $100 \mathrm{M}$ website views per year

At BMC, research is always in progress.

Learn more biomedcentral.com/submissions 